\title{
Anti-GITR Monoclonal Antibody
}

National Cancer Institute

\section{Source}

National Cancer Institute. Anti-GITR Monoclonal Antibody. NCI Thesaurus. Code C128058.

Any monoclonal antibody directed ag ainst the antigen glucocorticoid-induced TNFR-

related protein (GITR; tumor necrosis factor receptor superfamily member 18 (TNFRSF18). 